\title{
Nurses' Experiences of Health Promotion and Prevention of Cardiovascular Diseases Related to Smoking
}

\author{
Ernelind $N, B S N^{1 *}$, Wirkensjö $H, B S N^{1}$, Pangastuti HS, BSN, MSc ${ }^{2}$, Perdana $M, B S N, M S^{2}$, Widyawati \\ W, BSN, MPH, PhD'2 and Lepp M, RNT, PhD $D^{1,2,3,4}$
}

${ }^{1}$ Institute of Health and Care Science, The Sahlgrenska Academy, University of Gothenburg, Gothenburg, Sweden

${ }^{2}$ Faculty of Medicine, Public Health \& Nursing, Universitas Gadjah Mada, Yogyakarta, Indonesia

${ }^{3} \varnothing$ stfold University College, Halden, Norway

${ }^{4}$ School of Nursing and Midwifery, Griffith University, Australia

*Corresponding author: Nathalie Ernelind, Institute of Health and Care Science, The Sahlgrenska Academy, University of Gothenburg, Postal address: Schéelegatan 12b, 41660 Gothenburg, Sweden, Tel: +4676-580-7650

\begin{abstract}
Aim: The aim of the study is to describe nurses' experiences of working with health promotion and prevention of cardiovascular diseases related to smoking in Indonesia.

Methods: A phenomenographic approach was used. Semistructured interviews were conducted with nurses in health care centers and hospitals in Yogyakarta. The interviews were analysed according to Alexandersson's model.

Results: Three themes emerged from the analysis: Conceptions in relation to the patient and their family, conceptions in relation to the hospital and health care centers and conceptions in relation to the culture and policies. All nurses are working with health promotion and prevention of cardiovascular diseases related to smoking in one way or another. However, distinct guidelines and resources are missing. The nurses also mentioned the need of training in smoking cessation to better work with health promotion and prevention of cardiovascular diseases with a focus on smoking

Conclusion: The difficulties rise from lack of resources in the health care facilities, the patients' lack of motivation and weak policies from the government. For the situation to be improved the nurses need guidelines, training and more time to work with health promotion and prevention.

What this study adds:

Nurses stated that guidelines are not available to work with health promotion and smoking cessation in Indonesia. Nurses in Indonesia state they need training or retraining regarding the subject to be able to give good and proper education in tobacco cessation for cardiovascular ill patients.
\end{abstract}

Smoking is considered a tradition in Indonesia and the environment is not supportive for the ones who want to quit. Even though, involving the family shows to be a successful method for smoking cessation.

The implications of this paper:

Provide training in smoking cessation and in communication for Indonesian nurses to feel more secure when motivating the patients to quit smoking.

Establish specific guidelines to help and support the nurses in their work with cardiovascular diseases related to smoking.

Involving family is a successful approach that nurses can use in their work with smoking cessation which other studies also indicated.

\section{Keywords}

Cardiovascular diseases, Experience, Health promotion, Indonesian nurses', Nursing, Smoking cessation

\section{Introduction}

Cardiovascular diseases (CVDs) are the number one cause of death in the world. Over 17.5 million people die each year from cardiovascular diseases worldwide [1]. Smoking is the most essential preventable risk factor for CVDs and the issues concerning tobacco usage cause 6 million deaths each year worldwide $[2,3]$. More than 5 million of these deaths are caused by direct tobacco usage, 600,000 of the deaths, are caused exposed to non-smokers. Evidence show that

Citation: Ernelind N, Wirkensjö H, Pangastuti HS, Perdana M, Widyawati W, et al. (2019) Nurses' Experiences of Health Promotion and Prevention of Cardiovascular Diseases Related to Smoking. Int Arch Nurs Health Care 5:124. doi.org/10.23937/2469-5823/1510124

Accepted: May 25, 2019: Published: May 27, 2019

Copyright: (C) 2019 Ernelind N, et al. This is an open-access article distributed under the terms of the Creative Commons Attribution License, which permits unrestricted use, distribution, and reproduction in any medium, provided the original author and source are credited. 
both active and passive smoking generate decreased heart rate variability which is associated with negative cardiovascular health consequences. Most of the smokers, nearly $80 \%$, live in low or middle-income countries [3,4].

Indonesia as one of the developing countries also shows a great number of smokers. One third of Indonesian populations are smokers [5]. Smoking is not limited to occupation, social economic, or education level [6]. Around $60 \%$ of men in Indonesia are smokers, and in a report on the global tobacco epidemic from WHO [7] it was revealed that $21.4 \%$ of boys in the age of $13-15$ are current tobacco smokers. Both in urban and rural area, the number of tobacco smokers is almost the same. These circumstances contribute to higher incidence of cardiovascular diseases. It is reported that cardiovascular diseases are the number one cause of death in Indonesia [5]. The Indonesian government has formulated a seven basic program regarding smoking behavior. This program includes:

1. Declaring Government policy about cigarette and smoking behavior,

2. Health education for communities,

3. Health campagne through picture/poster,

4. Tobacco advertising regulation,

5. Smoking areas,

6. Health care services for smoking cessation,

7. National Health Care insurance for patients due to smoking $[8,9]$.

However, many politicians and researchers claim that the government policy and program are not well-implemented. Moreover, many stakeholders showed lower commitment in implementing the program which can be shown through a slow progression in act legitimation about tobacco control $[10,11]$. Further on, researchers also found that Indonesian government has a great economic burden in taking care of ill patients due to smoking [12]. Thus, smoking behavior is a prominent problem.

In order to overcome smoking behavior problem, a multidisciplinary approach is needed. Health professionals such as physicians, nurses, midwives, pharmacists and dentists play an important role in tobacco prevention. Tobacco control can be conducted by promotion of a non-smoking and tobacco free lifestyle. Education about the harms and effects of tobacco and exposure to second-hand smoke to the patients is a significant part of the health professionals' jobs [13].

WHO [14] mentioned that nurses play an important role in smoking cessation by giving advice, guidance and answer questions related to tobacco use and its health effects. However, in performing their role, nurses face many obstacles. For instance, many residents are ques- tioning the scientific evidence of negative impact in smoking, improperly connecting smoking behavior, economic status and occupation. And somehow, smoking behavior has become a common part of living among Indonesian people. Hence, even though nurses give health education to the residents due to smoking behavior, it has a little impact in decreasing the number of active smokers in Indonesia $[15,16]$.

Few studies have explored factors contributing to the expressed preferences for smoking cessation interventions. In a study by Sidani, et al. [17] about what smokers like and dislike about smoking cessation interventions, it was found that the majority of the participants prefered group behavioral therapy (54.4\%), and nicotine gum (45.6\%). The findings highlight the importance of assessing the smokers' perception and preferences when selecting cessation treatment.

Therefore, it is of great importance to understand and obtain knowledge of how nurses in Indonesia experience their work of promotion and prevention of cardiovascular diseases related to smoking. This study will provide knowledge about how nurses in Indonesia are involved in work regarding health promotion and prevention of cardiovascular diseases with a focus on smoking.

\section{Method}

\section{Aim}

The aim of this study is to describe nurses' experiences of working with health promotion and prevention of cardiovascular diseases related to smoking in Indonesia.

\section{Design}

This study used a phenomenographic approach. Phenomenography was first described in Sweden by Marton [18] as a research approach. It is particularly suitable when the aim is to collect a variety and broad range of experiences from a specific phenomenon. The objective of the phenomenographic approach is to describe the qualitatively different way a group of people make sense of, experience and understand phenomena in the world around them [19]. Interviews are common as a means of data collection within phenomenography $[20,21]$. In this study, the phenomenon was experiences of working with health promotion and prevention of cardiovascular diseases related to smoking.

\section{Participants}

Totally 10 female and 3 male nurses were recruited through strategic selection, six from three different health care centers and seven from one hospital in Yogyakarta, Indonesia. No exclusions regarding gender, age, religious beliefs or origins were implemented. The inclusion criteria were that all participants had to be nurses, by either bachelor degree or diploma degree, and have experiences of working with health promotion 
and prevention of cardiovascular diseases related to smoking in Indonesia. The range of the participants age was between 28-50 years and their work experience was between 2-27 years. Five participants have a bachelor degree and eight participants have a diploma degree. A Bachelor degree includes four years of academic studies and 1-1.5 year of a clinical phase. A Diploma degree includes 3 years for studying nursing integrated with an academic and clinical phase.

\section{Data collection}

A pilot test interview was conducted before beginning the data collection. The interviews started with reintroduced information about the aim of the study, followed by the main open interview question: their experiences of working with health promotion and prevention of cardiovascular diseases related to smoking. All interviews were recorded digitally. Two of the authors (NE and HW) carried out the interviews. The interviews lasted for 13-31 minutes. The translation process during the interviews was done by one of the researchers or a junior lecturer who is fluent in both Indonesian and English. Thus, back-translation process was directly performed in the interview process. The interviews were then transcribed verbatim by NE and $\mathrm{HW}$ and validated by MP and HSP.

\section{Ethical considerations}

This study builds on a thesis conducted by two nursing students (NE AND HW) from Gothenburg University, Sweden participating in an international exchange program. In accordance with Gadjah Mada University, Yogyakarta, Indonesia this study is ethically approved by their regulations. The participants received both written and verbal information about the study. Informed consent was given by all the participants before the interviews to ensure that the purpose of the study was understood and that their participation was voluntary. All gave their approval to participate and handed in a signed consent form.

\section{Analysis}

The analysis was performed according to the phenomenographic approach [22,23]. The four-step model from Alexandersson [24] was used to analyze the data. In the first step, all the interviews were read carefully several times after they had been transcribed verbatim, in order to obtain an overall impression of the material. The second step was devoted to noting similarities and differences in the material. In the third step, the statements were sorted into descriptive categories of conceptions. In the fourth and final step, the categories were reflected upon and the themes emerged, all describing the participants' experience of working with health promotion and prevention of cardiovascular diseases related to smoking.

\section{Trustworthiness}

The main question of credibility in phenomenographic research consists of the link between the empirical data and the categories for describing ways of experiencing a certain phenomenon. The researcher need to show that the elected way of describing differences and similarities is well supported by the empirical data. This can be done by supporting the relevance of the categories with quotes from the interviews. The credibility of the study is also based on the description of each part of the research process to make it feasible to replicate the study [22].

\section{Result}

The study participants were 10 female and 3 male, ranged in age from $28-50$ years. Eight with a diploma degree and five with a bachelor degree in nursing. Three themes with their attendant categories, representing different conceptions of working with health promotion and prevention of cardiovascular diseases related to smoking, emerged in the analysis of the interviews with the nurses (Table 1).

\section{Theme: Conceptions in relation to the patient and their family}

The first theme consists of three categories; "education and motivation to guide the patient", "involving the family align" and "changing the patients' mindset".

Category: Education and motivation to guide the patient: The first category includes conceptions related to the participants' experiences of education and motivation to guide the patient. The statements showed that the participants work starts with assessing the patient and their history of smoking. Education and promotion to the patients and their families was consid-

Table 1: Themes and categories.

\begin{tabular}{|l|l|}
\hline Themes & Categories \\
\hline $\begin{array}{l}\text { Conceptions in relation to the patient } \\
\text { and their family }\end{array}$ & $\begin{array}{l}\text { Education and motivation to guide the patient } \\
\text { Involving the family align } \\
\text { Changing the patients' mindset }\end{array}$ \\
\hline $\begin{array}{l}\text { Conceptions in relation to the hospital } \\
\text { and health care centers }\end{array}$ & $\begin{array}{l}\text { Limited time and funding } \\
\text { Insufficient training }\end{array}$ \\
\hline $\begin{array}{l}\text { Conceptions in relation to the culture } \\
\text { and policies }\end{array}$ & $\begin{array}{l}\text { The impact of the culture } \\
\text { Easy access to tobacco }\end{array}$ \\
\hline
\end{tabular}


ered highly important and included to give brochures or showing videos that explain the bad effects of smoking. Almost all participants stated that they did recommend the patients to stop smoking by providing motivation and encouragement. In one case the respondent tried to reduce the number of cigarettes and had follow-up appointments with the patient.

First I will motivate the patient about the bad thing about smoking... and then I try to reduce the number of cigarettes that the patient consumes.... So for three months every two weeks the patients will come to the clinic to have a motivation to reduce the consume of cigarettes ... gradually (2).

Even though the statements showed that the participants are working with education and motivation, a few stated this was only a short meeting and thereafter they would refer the patients to a smoking cessation clinic or a doctor for follow-up. The statements also revealed that in many cases the smoking cessation clinics are run by public health professions and not by nurses.

...At first I recommend the patient to quit smoke... But it's just a brief explanation. I will explain about the bad effect of smoking for the patients ... after the patient gets some explanation from the doctor, the doctor will refer this patient to the clinic. The special clinic for smoking cessation. And that clinic is run by public health professions (4).

Category: Involving the family align: The second category covers conceptions of involving the family align in the smoking cessation work. According to the statements, to engage family members to support the patient to stop smoking was considered a successful factor. A few participants said that if you educate the patient and their family about passive smoking and how the smoke will affect the wife and children it will be easier for the patient to quit.

So the most cases of success about smoking cessation is by involving the family member in the health education so an example, in the educational programme. I will also inform the wife (5).

According to the statements one reason that involving the family align would make it easier for the patient to quit smoking, is that they don't want their family to be exposed to the smoke:

Usually patients come when they want to quit smoking, when they have many diseases or they want to have children or they don't want to poison their children or their wife so they come to the clinic to stop smoking otherwise difficult (2).

Category: Changing patients' mindset: In the third category, statements about the difficulties of changing the patient's mindset are covered. Most of the participants claimed that changing the patients' mindset is the most difficult task. Statements also revealed that many patients continue to smoke when they get back home from the hospital although they participated in the education. This entails that the patient is coming back to the hospital because of symptoms from their diseases as they continue to smoke.

How to change the mindset of the patients is the most difficult for us. I think we always say that when the patients do not commit to stop smoking they need to remember the pain when they got the heart attack before they entered the unit (1).

Another suggestion is to increase the awareness and touch the heart of the patient and in this way make them want to stop by themselves.

... If the patient didn't want to stop so it also still not works. ... From me, the major thing that one tries is to touch the heart of the patient and make the patient understand and aware and make them want to stop by themselves.... (12).

\section{Theme: Conceptions in relation to the hospital and health care centers}

The second theme contains two categories "limited time and funding" and "insufficient training".

Category: Limited time and funding: The first category contains conceptions related to lack of time to plan for education:

So the first reason is because we have no much time for doing the educations. Because in one day we will have around 100 patients. Every nurse have around 3040 patients... it's very crowded and we don't have many times to do the health educations completely. ... So because we don't have much time to do the educations, we are not used to do that (4).

In addition, a few mentioned limitations of funding and low priorities for health promotion and prevention. The focus is essentially on curative care. Statements indicate that to make it easier to work with health promotion and prevention related to the subject there is a need for teamwork between departments.

The first thing to make it easier, we have to make a teamwork, with other department. In outpatient, the problem is the nurses are few and the patients are so many. So the nurse have a lack of time to give counseling (7).

Category: Insufficient training: The second category covers conceptions about working with no available guidelines and insufficient training. Only one participant had undergone training of working with health promotion and prevention regarding tobacco use. Most of the participants said that guidelines were not available and the participants had to learn by themselves to educate about tobacco cessation and work by their intuition.

The nurses who haven't got the training they will 
learn by themselves regarding how to quit smoking (3).

Almost all participants said that they need training or retraining regarding the subject to be able to give good and proper education in tobacco cessation for cardiovascular ill patients. In addition, a need for clear and specific guidelines was stated.

That is why kind of training or refreshing training regarding the role of nurses in giving education is very important.... In giving a good and proper educational programme, you need special skills. That's why I think training will be very beneficial (4).

\section{Theme: Conceptions in relation to the culture and policy}

The third theme consists of two categories, "the impact of the culture" and "easy access to tobacco".

Category: The impact of the culture: The first category covers statements about smoking as a tradition in Indonesia. In addition, smoking is considered masculine and cool.

Smoking is the tradition in Indonesia. It's a common habit. The children are smoking and the adults are smoking and the elders are smoking.... The teenager boy or men they have to smoke to "be cool" (7).

The participants said that the environment is not supportive for the ones who want to quit smoking as it is not tolerated by others:

Many patients say that the problem is the environment, not supportive enough to stop smoking. When they are meeting friends who also still smoke, it's not tolerated that themselves do not smoke (1).

In addition, the participants mentioned the joy that smoking could bring to people's lives and a big part of the Indonesian culture.

Category: Easy access to tobacco: The second category contains conceptions about policies related to advertisement and how easy it is to buy cigarettes in Indonesia. Some participants said that their work with health promotion and prevention regarding smoking is difficult since the policy is too weak and needs to be stricter. For example, according to the statements commercial advertisement is seen by children and teenagers with an arising interest in smoking:

And there are many commercial "iklan" (advertisement) here and many children or teenager watch it so they get interest to smoking. The policy of our government is so weak. Actually we have a policy not to smoking in public area. But it's not working (7).

Statements highlight that there is a policy regarding no smoking in hospitals and health care centers. It was mentioned the policy of buying cigarettes should be stricter:

In Indonesia there are no policy of selling cigarettes, they are free to sell to everyone regardless of age (13).

\section{Discussion}

We acknowledge several limitations. When making studies in another country linguistic and translation issues will appear, therefore one should get an interpreter who is culturally accepted and proficient in the language [25]. All of the participants spoke Bahasa or Javanese during the interviews, except for one nurse who spoke English fluently. Since the interviewers do not speak Bahasa or Javanese, an interpreter was needed. There were several different interpreters selected by Gadjah Madah University attending the interviews, of course only one at a time. Unfortunately, there were language barriers and sometimes the interpreters themselves might have influenced the answers. Parts where this was noticed was chosen to not be included in the study.

As only three of the nurses were men and ten were female, gender could have had an impact on the result. In Indonesia, most of nurses are female, this is also reflected in the comparison of the number of participants in this study who are dominated by female nurses. The proportion of Indonesian nurses is $71 \%$ female and $29 \%$ male [26].

Using a phenomenographic approach seems to have been a good choice, since many variations in the nurses' conceptions became clear in the findings. The statements showed that almost everyone recommended the patients to quit smoking. According to Venkatesh and Sinha [13], education to the patients about the effect of tobacco and exposure to passive smoke is a significant part of the nurses' work as health professionals. Haddock and Burrows [27] mean that nurses are well respected and have more contact with patients in the hospital than any other health profession. Therefore, the nurses have an important role and many opportunities to provide smoking cessation counseling.

Concerning involving family align, the statements showed that involving family members as support was a fortunate approach to make the patient stop smoking. This is supported by a study of Chan, Cheung, Fong, Emmons, Leung, Leung and Lam [28], where it was examined whether family based smoking cessation intervention for smoking fathers and nonsmoking mothers with a child was effective. The result indicated that the family based programme was effective in increasing the fathers' abstinence.

It was revealed that it was difficult to change the patients' mindset and make them commit to quit smoking. Statements showed that patients continued to smoke after hospitalization and that the smoking cessation not would work if the patient didn't want to quit themselves. Similar results are described in a study by Kotz, van Litsenburg, van Duurling, van Schayck \& Wesseling 
[29] where $65 \%$ of the nurses who participated considered that lack of patient's motivation is a barrier for smoking cessation treatment.

Concerning the category limited time and funding the most important result is that the nurses' experience that they don't have enough time to work with health promotion and prevention since the patients are so many and the nurses so few. This is in line with a study from Taggart [30] that showed that barriers such as lack of time and lack of systems for follow-up made it difficult to give health promotion advice.

Only one of the thirteen nurses had undergone any form of training in health promotion and prevention related to smoking and many nurses mentioned that training is important to give proper education to the patients. A study from Serbia showed that $60 \%$ of nurses who did not receive training in tobacco cessation felt unprepared to help patients quit smoking in contrast to $5 \%$ of nurses who received such training felt unprepared [31]. The statements also revealed that some nurses are insecure about if their workplaces have any guidelines to follow and many said that there are none. This makes it more difficult to work with health promotion and prevention. In the results from Barta and Stacy [32] where nurses participated in the Clinical practice guideline " 5 $A^{\prime} s^{\prime \prime}$ training program it was revealed that there was a significant difference in the nurses self-efficacy and behaviour for smoking cessation counseling from pretest to follow-up.

According to the nurses "everyone" is smoking in Indonesia, especially men. Smoking is considered to "be cool" and masculine. It is also in line with the study from Akhtar Hussain, et al. [33] where the results showed that tobacco smoking is the most prevalent risk factor for cardiovascular diseases among men in Indonesia.

It was also mentioned that the government policies' need to be stricter and statements indicated that the environment is not supportive for those who want to quit smoking. Regarding the policy of the government it was shown that cigarettes are very cheap and can be bought by anyone, even children. The result also revealed that government policies are considered weak and not supportive for the ones who try to quit smoking. This can be supported by the fact that there are no bans for direct advertisement of tobacco in Indonesia and you are still allowed to smoke in several public areas such as restaurants and indoor offices and workplaces WHO [7].

Mass media campaigns to promote tobacco cessation are essential investments as a part of a complete tobacco control programme. Changing beliefs and attitudes, educating about the effects of smoking, increasing intentions of quitting and reducing adult smoking prevalence can be supported by mass media campaigns [34].

To our knowledge, this is the first study performed on registered nurses in Yogyakarta, Indonesia with a qualitative approach regarding health promotion and prevention of cardiovascular diseases related to smoking.

\section{Conclusion}

This study shows that nurses do work with health promotion and prevention to try to make their patients quit smoking. However, difficulties appear from lack of resources in the health care facilities, the patients' lack of motivation and weak policies from the government. For the situation to be improved the nurses need guidelines to follow, training in tobacco cessation counseling and more time to work with health promotion and prevention. It would also be of advantage if the government in Indonesia would implement stricter policies regarding tobacco.

\section{Acknowledgement}

We thank all the participants in the study and the junior and senior lecturers at Gadjah Madah University.

\section{Conflict of Interest Statement}

The authors declare that there is no conflict of interest.

\section{References}

1. World Health Organization (2017) Cardiovascular disease.

2. Messner B, Bernhard D (2014) Smoking and cardiovascular diseases: Mechanisms of endothelial dysfunction and early atherogenesis. Arterioscler Thromb Vasc Biol 34: 509-515.

3. World Health Organization (2016) Tobacco.

4. Lee MS, Rees VW, Koutrakis P, Wolfson JM, Son YS, et al. (2019) Cardiac autonomic effects of secondhand exposure to nicotine from electronic cigarettes. Environmental Epidemiology 3: e033.

5. Kementerian Kesehatan RI (2017) Profil Kesehatan Indonesia Tahun 2016.

6. Riskesdas (2013) Riset Kesehatan Dasar. Badan penelitian dan pengembangan kesehatan kementerian kesehatan RI.

7. World Health Organization (2017) WHO report on the global tobacco epidemic - Country profile Indonesia.

8. Rochadi RK (2005) Berbagai upaya penanggulangan perilaku merokok di Indonesia.

9. Achadi A (2008) Regulasi Pengendalian Masalah Rokok di Indonesia. Journal Kesehatan Masyarakat Nasional 2: 161-165.

10. Hakam F (2015) Realita kebijakan pengendalian rokok di Indonesia: "Komitmen Pemerintah dan kepedulian masyarakat".

11. Yudho NK (2011) Pengendalian Rokok: Keseriusan Pemerintah dan Kepedulian Masyarakat. KaltengPos.

12. Hidayat B, Thabrany H (2008) Model Spesifikasi dinamis permintaan rokok: Rasionalkah perokok Indonesia. Journal Kesehatan Masyarakat Nasional 3: 99-108.

13. Venkatesh S, Sinha DN (2012) Involvement of health professionals in tobacco control in South-East Asia Region. Indian J Cancer 49: 327-335.

14. World Health Organization (2005) The role of health 
professionals in tobacco control.

15. Kementerian Kesehatan RI (2013) Profil Kesehatan Indonesia 2012.

16. Nichter M, Padmawati S, Danardono M, Ng N, Prabandari $Y$, et al. (2009) Reading culture from tobacco advertisements in Indonesia. Tobacco Control 18: 98-107.

17. Sidani S, Brewster J, Miranda J, Walkerly S, Belita E (2016) Exploring the contribution of treatment factors to preferences for smoking cessation interventions. Int Arch Nurs Health Care 2: 028.

18. Marton F (1981) Phenomenography - describing conceptions of the world around us. Instructional Science 10: $177-200$.

19. Marton F (1986) Phenomenography - A research approach to investigating different understandings of reality. Journal of Thought 21: 28-49.

20. Kitzinger J (1994) The methodology of focus groups: The importance of interaction between research participants. Sociology of Health \& IIIness 16: 103-121.

21. Krueger RA (1994) Focus Groups. A practical Guide for Applied Research. ( $2^{\text {nd }}$ edn), Sage Publications, Thousand Oaks.

22. SjöströmB, Dahlgren LO(2002)Applying phenomenography in nursing research. J Adv Nurs 40: 339-345.

23. Wenestam CG (2000) The phenomenographic method in health research. In: Qualitative Research Methods in the Service of Health. Studentlitteratur, Lund.

24. Alexandersson M (1994) Den fenomenografiska forskningsansatsens fokus. In: B Starrin, PG Svensson, Kvalitativ metod och vetenskapsteori. Studentlitteratur, Lund, s.111-s.136.

25. Kvale S (1997) Den kvalitativa forskningsintervjun. Studentlitteratur, Lund.
26. Kementerian Kesehatan RI (2017) Situasi tenaga keperawatan Indonesia. Pusat Data Dan Informasi.

27. Haddock J, Burrows C (1997) The role of the nurse in health promotion: An evaluation of a smoking cessation programme in surgical pre-admission clinics. J Adv Nurs 26: 1098-1110.

28. Chan SSC, Cheung YTD, Fong DYT, Emmons K, Leung AYM, et al. (2017) Family-based smoking cessation intervention for smoking fathers and nonsmoking mothers with a child: A randomized controlled trial. J Pediatr 182: 260-266.

29. Kotz D, van Litsenburg W, van Duurling $R$, van Schayck C, Wesseling GJ (2008) Smoking cessation treatment by Dutch respiratory nurses: Reported practice, attitudes and perceived effectiveness. Patient Educ Couns 70: 40-49.

30. Taggart MR (2009) The attitudes and activities of registered nurses towards health promotion and patient education in the emergency department. NENA Outlook 32: 15-19.

31. Merrill R, Gagon H, Harmon T, Milovic I (2010) The importance of tobacco cessation training for nurses in Serbia. J Contin Educ Nurs 41: 89-96.

32. Barta SK, Stacy RD (2005) The effects of a theory-based training program on nurses' self-efficacy and behavior for smoking cessation counseling. J Contin Educ Nurs 36: 117123.

33. Akhtar Hussain M, Al Mamun A, Peters SA, Woodward M, Huxley RR (2016) The burden of cardiovascular disease attributable to major modifiable risk factors in Indonesia. $J$ Epidemiol 26: 515-521.

34. Durkin S, Brennan E, Wakefield M (2012) Mass media campaigns to promote smoking cessation among adults: An integrative review. Tob Control 21: 127-138. 